\title{
Nonlinear Vibration Analysis of Functionally Graded Carbon Nanotubes Sandwich Cylindrical Panels
}

\author{
Senaa S. Hafidh ${ }^{1}$, Hamad M. Hasan², Farag M. Mohammed ${ }^{3}$
}

\section{Authors affiliations:}

1) Mechanical Department, University of Anbar. senaasamihafidh@gmail.com

2) Mechanical Department, University of Anbar. hamadscience155@gmail.com

3) Electromechanical Department, University of Technology, Baghdad- Iraq. drfaragmahel@yahoo.com

\section{Paper History:}

Received: $19^{\text {th }}$ Nov. 2019

Revised: $25^{\text {th }}$ Dec. 2019

Accepted: $16^{\text {th }}$ March 2020

\begin{abstract}
In this research, we investigate the nonlinear vibration of functionally graded carbon nanotubes (FG-CNTs) for simply supported sandwich cylindrical panels. The sandwich consisting of three layers formed of (FGCNTs) and isotropic material as (CNT, ALMINUME, CNT). Mechanical properties of the sandwich media are acquired according to a refined rule of blend approach. The governing equations were derived using a first-order deformation theory (FOSDT). Four kinds of carbon nanotubes of sandwich cylindrical panels were analyzed. The volume fraction of CNTs is varied. The properties of nonlinear responses and free vibration are studied. The numerical approach employs the fourth-order Runge-Kutta and Galerkine procedure. Which conducted for the dynamic analysis of the panels to present the natural frequencies and non-linear dynamic response expression. The results show that; the natural frequencies and the nonlinear vibration amplitude decrease with the volume fraction and thickness ratio increase. The nonlinear vibration amplitude response increases when increasing the excitation force. The initial imperfection and the elastic foundation have a minor impact on the nonlinear vibration response of the panel. The Pasternak Foundation has a larger impact than the Winkler foundation. The structure formed of FG-CNT present an excellent choice for highperformance of engineering applications.
\end{abstract}

Keywords: Sandwich Cylindrical Panels, Nonlinear Vibration, Functionally Graded Carbon Nanotube (FG-CNT), Imperfection Panel, First-Order Shear Deformation Theory.

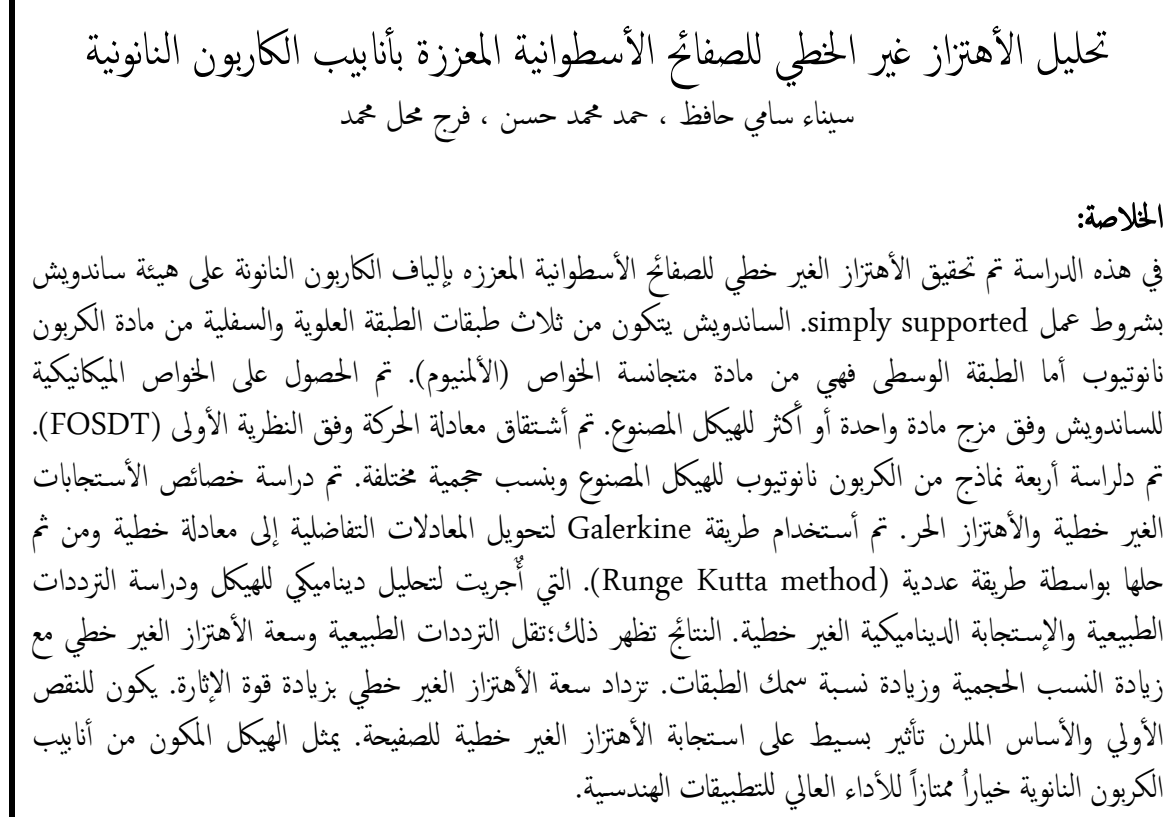

\section{Introduction}

The sandwich constructions are widely used in lots of areas of technology, for example, vehicles, marine, aerospace and so on. A sandwich cylindrical panel of functionally graded carbon nanotube and isotropic material is studied under various parameters. The improvement of nonlinear vibration behavior on the fundamental natural frequency of cylindrical panels in the form of sandwich is discussed in this study. The top and bottom sandwich

NJES is an open access Journal with ISSN 2521-9154 and eISSN 2521-9162

This work is licensed under a Creative Commons Attribution-NonCommercial 4.0 International License 
layers are made from a carbon nanotube. The carbon nanotubes have remarkable mechanical properties high modulus of elasticity, high mechanical strength, and high heat conductivity. It gives durability to the structure. While the core layer made from aluminum. Several methods have acquired to study the nonlinear vibration trouble by using functionally graded carbon nanotubes reinforced sandwich cylindrical panels. Sandwich structures have the following many advantages that; high durability, high modulus, low density, excellent resistance to wear and impact loads or vibration. To overcome problems such as delamination problems, so new types of sandwich structures: containing CNTs, core (aluminum) and CNTs introduced. CNT is a tubular form of carbon with a diameter as small as $1 \mathrm{~nm}$ Length: few $\mathrm{nm}$ to the micron. Allotropes of (graphite, diamond, amorphous carbon and Fullerene). In general, there are two kinds of carbon nanotubes a single-walled carbon nanotube (SWCNT) and a multi-walled carbon nanotube (MWCNT). The first type may be thought of as a single atomic layer thick sheet of graphene rolled into a seamless cylinder. While the second type may be consisting of multiple rolled layers (concentric tubes) of graphite Ping Zhu et al. [1] have a numerically studied with bending and free vibration analysis of thick composite plates built by single-walled carbon nanotubes using the finite element method founded on the first-order shear deformation plate theory. M.H. Yas et al. [2] studied the vibrational properties of functionally graded nanocomposite cylindrical panels reinforced by single-walled carbon nanotubes (SWCNTs), using the generalized differential quadrature (GDQ) method. Founded on the three-dimensional theory of elasticity. J. E. Jam et al. [3] inquired about the free vibration characteristics from nanocomposite cylindrical panels reinforced by single-walled carbon nanotubes applying the three-dimensional theory. A. Alibeigloo [4] investigated the behavior of free vibration behavior of functionally graded carbon nanotube-reinforced composite cylindrical panel embedded in piezoelectric layers by applying the three-dimensional theory of elasticity. Sofiyev [5]. Discussed the vibration and buckling of sandwich cylindrical shells covered by different kinds of coatings, for example functionally graded (FG) and metal and ceramic coatings applying first-order shear deformation theory. Z.X. Lei et al. [6] studied the nonlinear dynamic stability analysis of carbon nanotube-reinforced functionally graded cylindrical panels under static by applying the mesh-free KPRitz method. A.H. Sofiyev [7] investigated the dynamic instability of exponentially graded sandwich cylindrical shells under time-dependent occasional axial loadings applying the shear deformation theory. Sofiyev et al. [8] demonstrated the governing equations of dynamic stability for a sandwich cylindrical shell containing an FG core subjected to axial compressive load founded on Donnell's shell theory applying the shear deformation theory. HuiShen Shen [9] adopted cylindrical panels resting on elastic foundations submitted to lateral pressure in thermal environments applying higher-order shear deformation theory of carbon nanotube-reinforced composite. Y. Kiani [10] deals with the dynamic response of a functionally graded carbon nanotubereinforced composite cylindrical panel formulated within the framework applying first-order shear deformation shell theory. Wang et al. [11] conducted shells of revolution with arbitrary boundary conditions and applying the Ritz variation energy method with the semi-analytical method and its associated applications for linear vibration analysis of functionally graded carbon nanotube-reinforced composite (FG-CNTRC) doubly curved panels. Jianyu Fan et al. [12] investigate the free vibration of piezoelectric functionally graded carbon nanotubereinforced composite and elastically boundary conditions with applied the first-order shear deformation theory (FSDT) to conical panels. Gao et al. [13] studied the dynamic stability of (FGM) orthotropic cylindrical shell envelope founded on Hamilton's principle approach and von KarmanDonnell means by the elastic foundation under a linearly rising load with damping effect consideration. Ali Kemal Baltacioğlu et al. [14] gave a numerical solution for the free vibration problem of functionally graded and carbon nanotube reinforced (CNTR) circular cylindrical panel. founded on the Love's shell theory and first-order shear deformation theory. Qingya Li et al. [15] conducted an analytical method to study the dynamic buckling and nonlinear vibration of the graphene reinforced sandwich functionally graded porous plate. The investigated a functionally graded porous core and the GPL-SFGP plate consists of two metal face layers. Pham Toan Thang [16], investigated the nonlinear buckling behavior of the functionally graded carbon nanotube cylindrical shells applied on Donnell shell theory proposed a closed-form solution to submit to the compressive load.

\section{Expression of The Problem}

The sandwich consisting of three layers formed of functionally graded carbon nanotubes and isotropic material like aluminum (CNT, ALMINUME, CNT). The geometrical parameters of the cylindrical panels are thickness $h$, the radius of curvature $R$, elastic foundations (K1and K2) and length of edges a, b. A coordinate arrangement $(x, y, z)$ is selected, ( $x$ and $y$ ) is in the mid- surface of the panel while $z$ is in the thickness orientation of the panel, straight edge, curved edge, and thickness of the FG-CNTRC cylindrical panel. Reinforced composite cylindrical panel single-walled carbon nanotubes is shown in Fig. 1 [17].

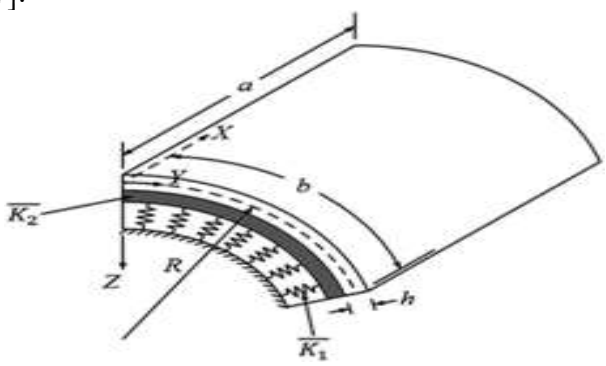

Figure (1): Geometrical parameters of cylindrical panel. 


\subsection{Material properties of CNTR}

The distribution of CNTs in a matrix may be functionally graded. In this study, four kinds of functionally graded along with the uniformly distributed case are considered. FGX-CNT, UDCNT, FGV-CNT, and FGO-CNT. The volume fraction of CNTs varies linearly with respect to the thickness and the accepted functionally graded distribution of CNTs in the polymeric matrix, [18] as:

$$
\begin{aligned}
& E_{11}(z)=\eta_{1} V_{C N T}(z) E_{11}^{c n t}+V_{m}(z) E^{m} \\
& \frac{\eta_{2}}{E_{22}(z)}=\frac{V_{C N T}(z)}{E_{22}^{c n t}}+\frac{V_{m}(z)}{E^{m}} \\
& \frac{\eta_{3}}{G_{12}(z)}=\frac{V_{C N T}(z)}{G_{12}^{c n t}}+\frac{V_{m}(z)}{G^{m}}
\end{aligned}
$$

In Eq. (1), These parameters are introduced to capture the size-dependent material properties of the FG-CNTRC cylindrical panel. The $\left(\eta_{1}, \eta_{2}, \eta_{3}\right)$ are the efficiency parameters in which be chosen to match the data obtained from the molecular dynamics' simulation. Besides, in Eq. (1). $E_{11}^{C N}, E_{22}^{C N}$ and $G_{12}^{C N}$ are the Young modulus and shear modulus, respectively. $E^{m}$ And $G^{m}$ indicate the corresponding properties of the isotropic matrix. The volume fraction of CNTs and matrix are denoted by $V_{C N T}$ and $V_{m}$ as:

$$
V_{m}(z)=1-V_{C N T}(z)
$$

In this research, four kinds of CNT distributions around the panel thickness are listed in Table1.

Table 1: Volume fraction of carbon nanotubes of thickness coordinate for different cases of CNTs distribution [18].

\begin{tabular}{|c|c|c|c|c|}
\hline $\begin{array}{c}\text { CNTs } \\
\text { Distribution }\end{array}$ & $\begin{array}{c}\text { FGX- } \\
\text { CNT }\end{array}$ & $\begin{array}{c}\text { UD- } \\
\text { CNT }\end{array}$ & $\begin{array}{c}\text { FGV- } \\
\text { CNT }\end{array}$ & $\begin{array}{c}\text { FGO- } \\
\text { CNT }\end{array}$ \\
\hline$V_{\text {tcnt }}$ & $4 \frac{|z|}{h} V_{\text {tcnt }}$ & $V_{\text {tcnt }}$ & $V_{\text {tctn }}\left(1+\frac{2 z}{h}\right)$ & $2 V_{\text {tctut }}\left(1-2 \frac{|z|}{h}\right)$ \\
\hline
\end{tabular}

Type FGX-CNT has a maximum near the top and bottom surfaces whereas the mid-plane is free of CNT. In FGV, the top surface is enriched with CNT and the bottom one is free of CNT. For FGO, however, top and bottom surfaces are free of CNTs and the mid-surface of the panel is enriched with CNTs. However, in UD-CNT type, each surface of the panel through the thickness has the same volume fraction of CNTs.

Poisson ratio depends weakly on position [18] as:

$$
v=V_{t c n t} v^{C N}+V_{m} v^{m}
$$

The mass density of the composite cylindrical panel media is a conventional rule of mixtures approach as [18]:

$$
\rho=V_{C N} \rho^{C N}+V_{m} \rho^{m}
$$

Where:

$\rho^{C N}$ and $\rho^{m}$ are the mass density of the carbon nanotube with the matrix.

The variation of young's modulus, poison's proportion and density of FG-CNT sandwich panel are applied [7]:

$$
[E(z), v(z), \rho(z)]=\left\{\begin{array}{l}
E_{C N}^{(1)}, v_{C N}^{(1)}, \rho_{C N}^{(1)} \\
E_{A l}^{(2)}, v_{A l}^{(2)}, \rho_{A l}^{(2)} \\
E_{C N}^{(3)}, v_{C N}^{(3)}, \rho_{C N}^{(3)}
\end{array}\right\}
$$

\subsection{Fundamental relations and basic equations}

The displacement area of the panel problem is established agreeing to the first-order shear theory as [18]:

$$
\begin{aligned}
& U(x, y, z)=u(x, y, t)+z \phi_{x}(x, y, t) \\
& V(x, y, z)=v(x, y, t)+z \phi_{y}(x, y, t) \\
& W(x, y, z)=w(x, y, t)
\end{aligned}
$$

Where $\phi_{x}$ and $\phi_{y}$ are the rotations of the normal to the middle surface about the $\mathrm{y}$ and $\mathrm{x}$ directions, $u, v$ and $w$ denote the displacements of the corresponding point on the middle surface in the $\mathrm{x}, \mathrm{y}$ and $z$ directions, and $t$ is the time.

The strain-displacement relationships with the Von Karman [18]:

$$
\begin{gathered}
\varepsilon_{x}=\varepsilon_{x}^{\circ}+z \chi_{x} \\
\varepsilon_{y}=\varepsilon_{y}^{\circ}+z \chi_{y} \\
\gamma_{x y}=\gamma_{x y}^{\circ}+z \chi_{x y} \\
\gamma_{x z}=\gamma_{x z}^{\circ} \\
\gamma_{y z}=\gamma_{y z}^{\circ} \\
\left(\begin{array}{l}
\varepsilon_{x}^{\circ} \\
\varepsilon_{y}^{\circ} \\
\gamma_{x y}^{\circ}
\end{array}\right)=\left(\begin{array}{l}
\frac{\partial u}{\partial x}+\frac{1}{2}\left(\frac{\partial w}{\partial x}\right)^{2} \\
\frac{\partial v}{\partial y}-\frac{w}{R}+\frac{1}{2}\left(\frac{\partial w}{\partial x}\right)^{2} \\
\frac{\partial u}{\partial y}+\frac{\partial v}{\partial x}+\frac{\partial w}{\partial x} \frac{\partial w}{\partial y}
\end{array}\right),\left(\begin{array}{l}
\chi_{x} \\
\chi_{y} \\
\chi_{x y}
\end{array}\right)= \\
\left(\begin{array}{l}
\frac{\partial \phi_{x}}{\partial x} \\
\frac{\partial \phi_{y}}{\partial y} \\
\frac{\partial \phi_{x}}{\partial y}+\frac{\partial \phi_{y}}{\partial x}
\end{array}\right)
\end{gathered}
$$

$\mathrm{U}, \mathrm{v}$, and ware displacement elements respect to the coordinates $(\mathrm{x}, \mathrm{y}, \mathrm{z}), \varepsilon_{x}^{\circ}$ and $\varepsilon_{y}^{\circ}$ as the normal strains, and $\gamma_{x y}^{\circ}, \gamma_{x z}^{\circ}, \gamma_{y z}^{\circ}$ described the shear strain of the panel in the center surface. The compatibility equation of an imperfect FG-CNTRC cylindrical panels can be founded by employing eq. (7) and eq. (8) for follow: 
$\frac{\partial^{2} \varepsilon_{x}^{0}}{\partial y^{2}}+\frac{\partial^{2} \varepsilon_{y}^{0}}{\partial x^{2}}-\frac{\partial^{2} \gamma_{x y}^{0}}{\partial x \partial y}=\frac{\partial^{2} w^{2}}{\partial x \partial y}-\frac{\partial^{2} w}{\partial x^{2}} \frac{\partial^{2} w}{\partial y^{2}}+2 \frac{\partial^{2} w}{\partial x \partial y} \frac{\partial^{2} w^{*}}{\partial x \partial y}-\frac{\partial^{2} w}{\partial x^{2}} \frac{\partial^{2} w^{*}}{\partial y^{2}}$

$-\frac{\partial^{2} w}{\partial y^{2}} \frac{\partial^{2} w^{*}}{\partial x^{2}}-\frac{1}{R_{y}} \frac{\partial^{2} w}{\partial x^{2}}$

Hooke's law for a panel is defined as:

$$
\left\{\begin{array}{l}
\sigma_{x} \\
\sigma_{y} \\
\sigma_{x y} \\
\sigma_{x z} \\
\sigma_{y z}
\end{array}\right\}=\left\{\begin{array}{ccccc}
Q_{11}(z) & Q_{12}(z) & 0 & 0 & 0 \\
Q_{21}(z) & Q_{22}(z) & 0 & 0 & 0 \\
0 & 0 & Q_{66}(z) & 0 & 0 \\
0 & 0 & 0 & Q_{55}(z) & 0 \\
0 & 0 & 0 & 0 & Q_{44}(z)
\end{array}\right\}\left\{\begin{array}{c}
\varepsilon_{x} \\
\varepsilon_{y} \\
\gamma_{x y} \\
\gamma_{x z} \\
\gamma_{y z}
\end{array}\right\} \ldots(10)
$$

Where $Q_{i j}(i, j=1,2,4,5,6)$ are the abbreviated material tightened up coefficients compatible with conditions and are found as follow:

$$
\begin{aligned}
& Q_{11}=\frac{E_{11}}{1-v^{2}}, Q_{22}=\frac{E_{22}}{1-v^{2}}, Q_{12}=\frac{v_{12} E_{11}}{1-v^{2}}, Q_{44}= \\
& G_{23}, Q_{55}=G_{13}, Q_{66}=G_{12} .
\end{aligned}
$$

Force and moment resultants of sandwich panels:

$$
\left\{\begin{array}{l}
N_{x} \\
N_{y} \\
N_{x y} \\
M_{x} \\
M_{y} \\
M_{x y} \\
Q_{x} \\
Q_{x}
\end{array}\right\}=\left[\begin{array}{cccccccc}
A_{11} & A_{12} & 0 & B_{11} & B_{12} & 0 & 0 & 0 \\
A_{21} & A_{22} & 0 & B_{12} & B_{22} & 0 & 0 & 0 \\
0 & 0 & A_{66} & 0 & 0 & B_{66} & 0 & 0 \\
B_{11} & B_{12} & 0 & D_{11} & D_{12} & 0 & 0 & 0 \\
B_{12} & B_{22} & 0 & D_{12} & D_{22} & 0 & 0 & 0 \\
0 & 0 & 0 & 0 & 0 & D_{66} & 0 & 0 \\
0 & 0 & 0 & 0 & 0 & 0 & k A_{55} & 0 \\
0 & 0 & 0 & 0 & 0 & 0 & 0 & k A_{44}
\end{array}\right]\left\{\begin{array}{l}
\varepsilon_{x}^{\circ} \\
\varepsilon_{y}^{\circ} \\
\gamma_{x y}^{\circ} \\
\chi_{x} \\
\chi_{y} \\
\chi_{x y}^{\circ} \\
\gamma_{x z}^{\circ} \\
\gamma_{y z}^{\circ}
\end{array}\right\} \ldots(1
$$

Where $A_{i j}, B_{i j}$ and $D_{i j}$ are constants. The relationships of the strain-force resultant reversely are accepted eq. (12)

$$
\left\{\begin{array}{l}
\varepsilon_{x}^{\circ}=A_{22} N_{x}-A_{12} N_{y}-B_{11} \frac{\partial \phi_{x}}{\partial x}-B_{22} \frac{\partial \phi_{y}}{\partial y} \\
\varepsilon_{y}^{\circ}=A_{11} N_{y}-A_{12} N_{x}-B_{12} \frac{\partial \phi_{x}}{\partial x}-B_{22} \frac{\partial \phi_{y}}{\partial y} \\
\gamma_{x y}^{\circ}=A_{66} N_{x y}-B_{66}\left(\frac{\partial \phi_{x}}{\partial y}+\frac{\partial \phi_{y}}{\partial x}\right)
\end{array}\right\}
$$

The constants were extracted in a numerical way (Simpson method), using the FORTRAN program because it is not integrated in analytical method as [19]:

$$
\left(A_{i j}, B_{i j}, D_{i j}\right)=\int_{-h / 2}^{h / 2} Q_{i j}\left(1, z, z^{2}\right) d z
$$

The stress function $f(x, y, t)$ is presented as:

$N_{x}=\frac{\partial^{2} f}{\partial y^{2}}, N_{y}=\frac{\partial^{2} f}{\partial x^{2}} \operatorname{and} N_{x y}=-\frac{\partial^{2} f}{\partial x \partial y}$

Replacement of eq. (13) into eq. (9) the compatibility provides of imperfect FG-CNTRC cylindrical panels equation and eq. (12) and eq. (8) and Airy function yields:
$A_{11} \frac{\partial^{4} f}{\partial x^{4}}+A_{22} \frac{\partial^{4} f}{\partial y^{4}}+\left(A_{66}-2 A_{12}\right) \frac{\partial^{4} f}{\partial x^{2} \partial y^{2}}-$

$B_{21} \frac{\partial^{3} \phi_{x}}{\partial x^{3}}-B_{12} \frac{\partial^{3} \phi_{y}}{\partial y^{3}}+\left(B_{66}-B_{11}\right) \frac{\partial^{3} \phi_{x}}{\partial x \partial y^{2}}+\left(B_{66}-\right.$

$\left.B_{22}\right) \frac{\partial^{3} \phi_{y}}{\partial x^{2} \partial y}-\left(\frac{\partial^{2} w^{2}}{\partial x \partial y}-\frac{\partial^{2} w}{\partial x^{2}} \frac{\partial^{2} w}{\partial y^{2}}+\quad 2 \frac{\partial^{2} w}{\partial x \partial y} \frac{\partial^{2} w^{*}}{\partial x \partial y}-\right.$ $\left.\frac{\partial^{2} w}{\partial x^{2}} \frac{\partial^{2} w^{*}}{\partial y^{2}}-\frac{\partial^{2} w}{\partial y^{2}} \frac{\partial^{2} w^{*}}{\partial x^{2}}-\frac{1}{R y} \frac{\partial^{2} w}{\partial x^{2}}\right)=0$

Eq. (16) represents the equations of nonlinear through the variable $(f$ and $w)$ which are utilized to study the nonlinear vibration doings of sandwich FGCNTs cylindrical panels built on elastic foundations by applying first-order shear deformation theory (FSDT).

\section{Boundary condition and result}

In this part, the boundary conditions of FG-CNTRC cylindrical panels are simply supported, under the unvarying diffused pressure of strength (q). The boundary conditions are employed to explain the (FG-CNT) thick cylindrical panels which may be obtained as given below [20]:

$w=M_{x}=N_{x y}=0, N_{x}=0, a t x=0, a$,

$w=M_{y}=N_{x y}=0, N_{y}=0$, aty $=0, b$,

To satisfy the conditions given in eq. (17), the mode shape is expressed as follows:

$w(x, y, t)=W(t) \sin \lambda_{m} x \sin \delta_{n} y$,

$\phi(x, y, t)=\phi_{x}(t) \cos \lambda_{m} x \sin \delta_{n} y$,

$\phi(x, y, t)=\phi_{y}(t) \sin \lambda_{m} x \cos \delta_{n} y$,

Where $\lambda_{m} \frac{m \pi}{a}, \delta_{n}=\frac{n \pi}{b}, m, n=1$ The natural counts of half-waves in the agreeing direction $\mathrm{x}, \mathrm{y}, \mathrm{W}$ (t) the time-dependent and $\phi_{x}, \phi_{y}$ the amplitudes are functions of the time.

The initial imperfection $w^{*}$ geometric of a cylindrical panel is accepted as:

$$
w^{*}(x, y)=W_{\circ}(t) \sin \lambda_{m} x \sin \delta_{n} y,
$$

Where the coefficient $W_{\text {。 }}$ magnitude of initial imperfection at a center of the panels.

Aside from standing in eq. (18) and eq. (19) into eq. (17), Airy stress function $f$ can be defined as follows:

$f(x, y, t)=A_{1}(t) \cos 2 \lambda_{m} x+A_{2} \cos 2 \delta_{n} y+$ $A_{3}(t) \sin \lambda_{m} x \sin \delta_{n} y$

Where

$$
\begin{gathered}
A_{1}=\frac{\delta_{n}^{2}}{32 A_{11} \lambda_{m}^{2}} W\left(W+2 W_{\circ}\right), A_{2} \\
=\frac{\lambda_{m}^{2}}{32 A_{22} \delta_{n}^{2}} W\left(W+2 W_{\circ}\right), \\
A_{3}=\frac{1}{\left[\lambda_{m}^{4} A_{11}+\delta_{n}^{4} A_{22}+\left(A_{66}-2 A_{12}\right) \lambda_{m}^{2} \delta_{n}^{2}\right]} \frac{\lambda_{m}^{2}}{R_{y}}+ \\
\frac{B_{21} \lambda_{m}^{3} \phi_{x}+B_{12} \delta_{n}^{3} \phi_{y}+\left(B_{11}-B_{66}\right) \phi_{x} \lambda_{m} \delta_{n}^{2}+\left(B_{22}-B_{66}\right) \phi_{y} \lambda_{m}^{2} \delta_{n}}{\left[\lambda_{m}^{2} A_{11}+\delta_{n}^{2} A_{22}+\left(A_{66}-2 A_{12}\right) \lambda_{m}^{2} \delta_{n}^{2}\right]},
\end{gathered}
$$


last, the nonlinear equations can be found and the load-deflection curve could be sought by substituting eq. (18) and eq. (20) from eq. (16) and then using the Galerkin method.

$I_{\circ} \frac{d^{2} W}{d t^{2}}-l_{11} W-l_{12} \Phi_{x}-l_{13} \Phi_{y}-l_{14}(W+$

$\left.W_{\circ}\right) \Phi_{x}-l_{15}\left(W+W_{\circ}\right) \Phi_{y}-n_{1}\left(W+W_{\circ}\right)-$

$n_{2} W\left(W+W_{\circ}\right)+n_{3} W\left(W+2 W_{\circ}\right)+n_{4} W W_{\circ}(W+$

$\left.2 W_{\circ}\right)=n_{5} Q \sin \Omega t$

For an ideal shell, the fundamental frequencies can be obtained as:

$$
\omega_{m n}=\sqrt{-\frac{\left(a_{1}+a_{2}\right)}{I_{\circ}}},
$$

Consider the nonlinear vibration of a complete panel, eq. (22) has of the form

$I_{\circ} \frac{d^{2} W}{d t^{2}}-\left(a_{1}+a_{2}\right) W-\left(a_{3}+a_{4}+a_{6}\right) W^{2}-$

$a_{5} W^{3}=n_{5} Q \sin \Omega t$.

Where:

$a_{1}=l_{11}+l_{12} \frac{l_{23} l_{31}-l_{21} l_{33}}{l_{22} l_{33}-l_{23} l_{32}}+l_{13} \frac{l_{32} l_{21}-l_{31} l_{22}}{l_{22} l_{33}-l_{23} l_{32}}, a_{2}=$

$n_{1}+l_{12} \frac{l_{23} n_{9}-l_{33} n_{7}}{l_{33} l_{22}-l_{23} l_{32}}+l_{13} \frac{l_{32} n_{7}-l_{22} n_{9}}{l_{33} l_{22}-l_{23} l_{32}}$,

$a_{3}=n_{2}+l_{14} \frac{l_{23} l_{31}-l_{21} l_{33}}{l_{33} l_{22}-l_{23} l_{32}}+l_{15} \frac{l_{32} l_{21}-l_{31} l_{22}}{l_{33} l_{22}-l_{23} l_{32}}, \quad a_{4}=$

$n_{3}+l_{12} \frac{l_{23} n_{10}-l_{33} n_{8}}{l_{33} l_{22}-l_{23} l_{32}}+l_{13} \frac{l_{32} n_{8}-l_{22} n_{10}}{l_{33} l_{22}-l_{23} l_{32}}$,

$a_{5}=n_{4}+l_{14} \frac{l_{23} n_{10}-l_{33} n_{8}}{l_{33} l_{22}-l_{23} l_{32}}+l_{15} \frac{l_{32} n_{8}-l_{22} n_{10}}{l_{33} l_{22}-l_{23} l_{32}}, a_{6}=l_{14}$

Eq. (24) can be rewritten as

$\frac{d^{2} W}{d t^{2}}+\omega_{m n}^{2}\left(W+M W^{2}+N W^{3}\right)-F \sin \Omega t=0$,

\section{Numerical Results}

These properties are taken from the previous research $[17,18]$, as the properties are accepted to be as: $\quad E_{m}=2.5 \quad \mathrm{GPA}, \quad v_{m}=0.34$ and $\rho_{m}=$ $1150 \mathrm{Kg} / \mathrm{m}^{3}$. In this analysis, the properties of SWCNTs are chosen as follows: $E_{11}^{C N T}=2.546 \mathrm{TPA}$, $E_{22}^{C N T}=7.08 \mathrm{TPA}, \quad G_{12}^{C N T}=1.944 \mathrm{TPA}, \quad v^{C N T}=$ 0.175 and $\rho^{C N T}=1400 \mathrm{Kg} / \mathrm{m}^{3}$. The detailed material attributes of CNT efficiency parameters, for three dissimilar CNTs volume fraction values of these CNT efficiency parameters are: $\eta_{1}=0.137, \eta_{2}=$ 1.022 and $\eta_{3}=0.715$ for $V_{t c n t}=0.12$; $\eta_{1}=0.142, \eta_{2}=1.626$ and $\eta_{3}=1.138$ for $V_{t c n t}=0.17 \quad ; \eta_{1}=0.141, \eta_{2}=1.585$ and $\quad \eta_{3}=$ 1.1095 for $V_{t c n t}=0.28$, and properties of unity isotropic material $(\mathrm{Al}): E_{m}=7 \times e 10 \mathrm{~Pa}, v_{m}=0.3$ and $\rho_{m}=2702 \mathrm{Kg} / \mathrm{m}^{3}$.

\subsection{Validation of The Present Formulation}

Consider a functionally graded carbon nanotube sandwich cylindrical panels submitted to a uniformly cross distributed load where (Q) represented the amplitude of excited load. Table 2 compares the values of the natural frequencies of FG-CNTRC panels $(m, n)=(1,1), a / R=1, a / b=1$, and $a / h=20)$ with several graded profiles of CNTs, the various volume fraction of CNTs were compared with results of Y. Kiani et al. [21] for cylindrical panels with simply supported edges plate. Figs. (2, 3, 4 and 5) show the effects of different volume fractions on natural frequency around the panel thickness founded on the FOSDT. The results show that with the volume fraction increase the amplitude of the dynamic response of cylindrical panel decrease. The FGXCNT presents higher frequencies amplitude rather than the other panels, while FGO-CNT panels have the minimum one.

Table 2: Fundamental natural frequency by Ref. [21]

\begin{tabular}{|c|c|c|c|}
\hline $\boldsymbol{V}_{\boldsymbol{C N T}}^{*}$ & $\begin{array}{c}\text { Types of } \\
\text { CNT }\end{array}$ & Ref.[21] & Present(FST) \\
\hline \multirow{5}{*}{0.12} & FGX & 23.2763 & 22.1009 \\
& UD & 21.4707 & 18.2024 \\
& FGV & 21.2857 & 17.9555 \\
& FGO & 19.1857 & 10.7592 \\
\hline \multirow{4}{*}{0.17} & FGX & 29.5672 & 26.4959 \\
& UD & 27.0582 & 21.1351 \\
& FGV & 26.9125 & 21.1337 \\
& FGO & 24.1626 & 12.1269 \\
\hline \multirow{3}{*}{0.28} & FGX & 33.8769 & 32.3070 \\
& UD & 30.1508 & 26.7468 \\
& FGV & 30.2290 & 26.7427 \\
& FGO & 26.3956 & 17.0318 \\
\hline
\end{tabular}

Figs. $(2,3,4,5)$ represented the influence of volume $\frac{l_{23} n_{9}-l_{33} n_{2}}{l_{33} l_{22}-l_{23} l_{32}}$ panel at $Q \stackrel{l_{33} l_{2}}{=} 4^{2} 00_{23} \mathrm{~N}^{2} / \mathrm{m}^{2}, \Omega=400 \mathrm{rad} / \mathrm{sec}, \mathrm{W} 0=0$ and $(\mathrm{a}=\mathrm{b}=\mathrm{R}=1 \mathrm{~m}),(\mathrm{h}=0.05 \mathrm{~m})$.

In the Figs. $(2,3,4,5)$ noted that the value of volume fraction decrease, it is offset by an increase in the amplitude of dynamic response of cylindrical panel due to the material mechanical properties increased. The high amplitude is introduced with using FGX-CNT while the lowest amplitude value is with using FGO-CNT as shown in Fig. (6) that represents the dynamic response of sandwich cylindrical panels at $V_{C N T}^{*}=0.28$.

$$
1 \times 10^{-4}
$$

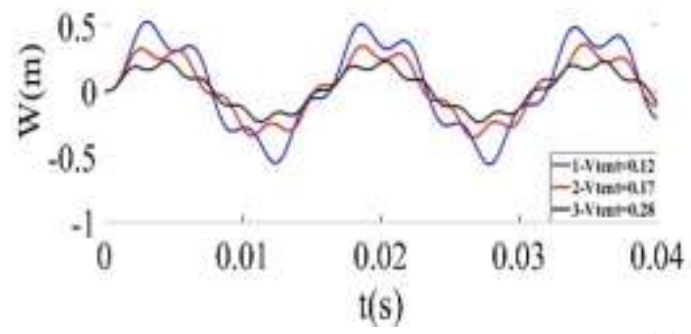

Figure (2): Dynamic response of FGX-CNT cylindrical panels. 


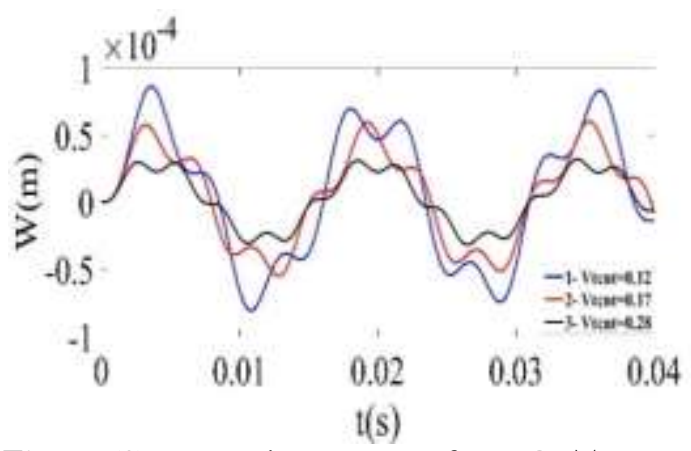

Figure (3): Dynamic response of UD-CNT cylindrical panels.

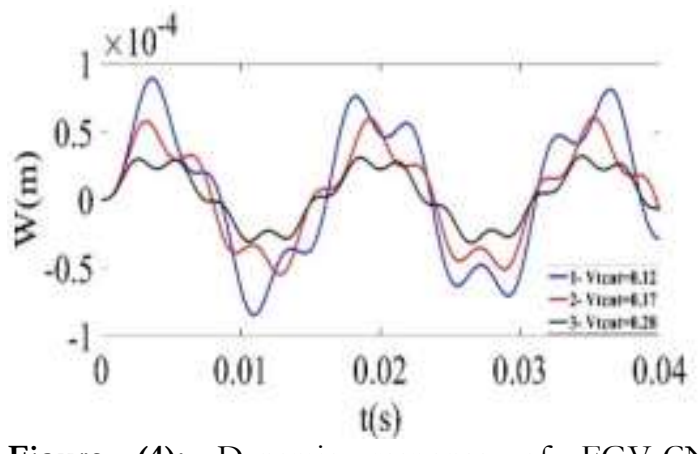

Figure (4): Dynamic response of FGV-CNT cylindrical panels.

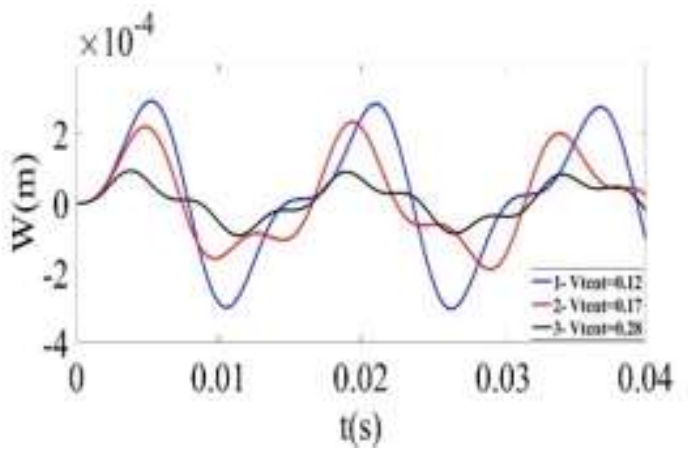

Figure (5): Dynamic response of FGO-CNT cylindrical panels.

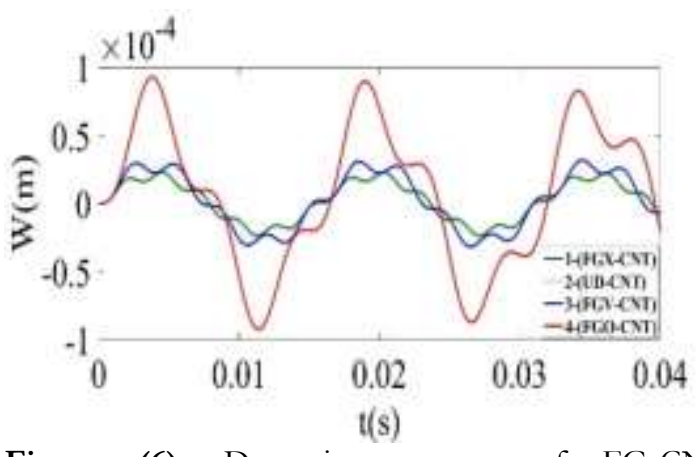

Figure (6): Dynamic response of FG-CNT cylindrical panels at $V_{C N T}^{*}=0.28$.
Table 3: natural frequency parameter $\widetilde{\boldsymbol{\omega}}=$ $\boldsymbol{\omega} \boldsymbol{R} \sqrt{\boldsymbol{\rho} / \boldsymbol{E}}$ for cylindrical panels for middle layer isotropic material.

\begin{tabular}{|c|c|c|c|c|c|c|}
\hline B.Cs. & Geometry & Source & $\begin{array}{c}\mathrm{m}=1 \\
\mathrm{n}=1\end{array}$ & $\begin{array}{c}\mathrm{m}=2 \\
\mathrm{n}=2\end{array}$ & $\begin{array}{c}\mathrm{m}=3 \\
\mathrm{n}=3\end{array}$ & $\begin{array}{c}\mathrm{m}=4 \\
\mathrm{n}=4\end{array}$ \\
\hline & $\begin{array}{c}\mathrm{a}=3 \mathrm{~m}, \\
\mathrm{~b}=3.1415 \mathrm{~m}, \\
\mathrm{R}=2 \mathrm{~m}, \\
\mathrm{~h}=0.02 \mathrm{~m} \\
p=7800 \mathrm{~kg} / \mathrm{m}^{3} \\
\mathrm{E}=210 \mathrm{GPa}\end{array}$ & Ref.[21] & 0.24474 & 0.25796 & 0.34446 & 0.38700 \\
SSSS & & & 0.4599 & 0.5762 & 0.8094 \\
& & & & & & \\
\hline
\end{tabular}

\subsection{Influence of Thickness of FG-CNT}

The influence of the core-to-CNT thickness ratio [7] $h_{\text {core }} / h_{C N T}=(2,4,6)$ on the natural frequency of cylindrical panels reinforced composite with FGCNT layers and isotropic material layer is shown in Fig. (7, 8, 9 and 10), basis of first-order shear deformation theory with $(\mathrm{m}, \mathrm{n})=(1,1)$ is presented in Table 3. Ash $h_{\text {core }} / h_{C N T}=2$, in this case, the thickness of the layers is $h_{C N T}=h / 4, h_{\text {core }}=h / 2$ [7] and cylindrical panel characteristics are taken to be $R / h=25 . \quad A s h_{\text {core }} / h_{C N T}=4$, the carbon nanotube layers are the sandwich panel, i.e. $h_{C N T}=$ $h / 6, h_{\text {core }}=2 h / 3 \quad$ [7] and cylindrical panel characteristics are taken to be $R / h=50$. Ash $h_{\text {core }} /$ $h_{C N T}=6$, in this case, the carbon nanotube layers are the sandwich panel. So, $h_{C N T}=h / 8, h_{\text {core }}=$ $3 h / 4$ [7] and cylindrical panel characteristics are taken to be $R / h=75$, for all cases assume $R=1$, as the core to CNT thickness ratio increases from 2 to 6. Sandwich cylindrical panels are designed $\mathrm{CNT} / \mathrm{Al} / \mathrm{CNT}$.

Table 4: Results of a thickness of three layers (CNT, $\mathrm{Al}, \mathrm{CNT}$ ) on the nonlinear vibration reaction of sandwich cylindrical panels $\mathrm{a}=\mathrm{b}=\mathrm{R}=1 \mathrm{~m}, \mathrm{~K} 1=\mathrm{K} 2=0$, $\mathrm{q} 0=4000 \sin 400 \mathrm{t}$.

\begin{tabular}{|c|c|c|c|}
\hline$V_{C N}^{*}$ & $\begin{array}{l}\text { Thickness } \\
\text { (h) }\end{array}$ & $\begin{array}{l}\text { Type } \\
\text { of } \\
\text { CNT }\end{array}$ & $\begin{array}{c}\text { Natural } \\
\text { frequency }(\mathrm{rad} / \mathrm{sec})\end{array}$ \\
\hline \multirow{3}{*}{0.12} & 0.04 & $\begin{array}{c}\text { FGX } \\
\text { UD } \\
\text { FGV } \\
\text { FGO }\end{array}$ & $\begin{array}{l}49.0362 \\
44.7193 \\
43.6867 \\
62.7467 \\
\end{array}$ \\
\hline & 0.02 & $\begin{array}{l}\text { FGX } \\
\text { UD } \\
\text { FGV } \\
\text { FGO }\end{array}$ & $\begin{array}{c}90.8730 \\
91.0019 \\
91.0019 \\
115.7371\end{array}$ \\
\hline & 0.0133 & $\begin{array}{l}\text { FGX } \\
\text { UD } \\
\text { FGV } \\
\text { FGO }\end{array}$ & $\begin{array}{l}137.0796 \\
140.0934 \\
137.5181 \\
180.5375\end{array}$ \\
\hline
\end{tabular}

Fig. (7) represented the influence of thickness of FG-CNT and isotropic material cylindrical panels on dynamic response of sandwich cylindrical panel at $Q=4000 \mathrm{~N} / \mathrm{m}^{2}, \Omega=400 \mathrm{rad} / \mathrm{sec}$ and $\mathrm{W} 0=0$. In the figs. of $(\mathrm{a}, \mathrm{b}, \mathrm{c}, \mathrm{d})$ noted that the value of thickness 
decrease, it is offset by an increase in the amplitude of dynamic response of cylindrical panel due to the structure that is more stiff. The structure is more stable in distributed FGO-CNT due to the increase in the thickness of the inner layer with the stability of thickness upper and lower layers from CNTs as shown in Fig. (8) that represent the nonlinear vibration response of sandwich panel at $\mathrm{h}=0.04 \mathrm{~m}$ and $V_{C N T}^{*}=0.12$.

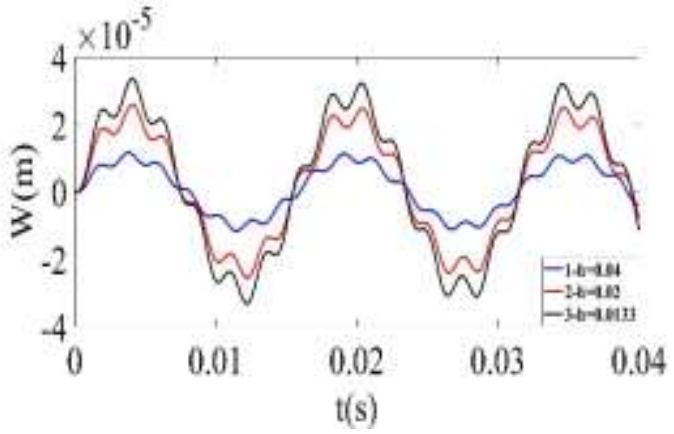

(a)

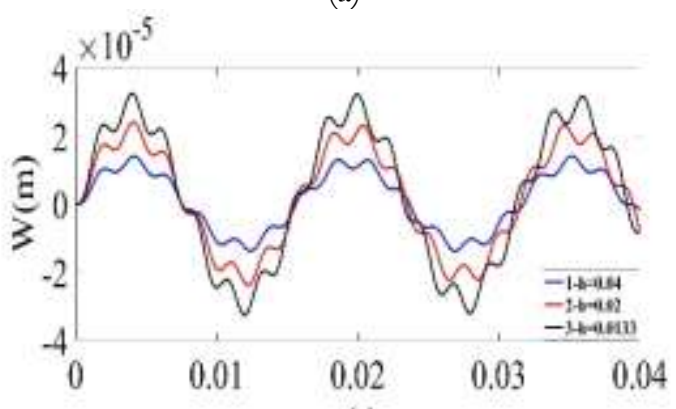

$\mathrm{t}(\mathrm{s})$

(b)

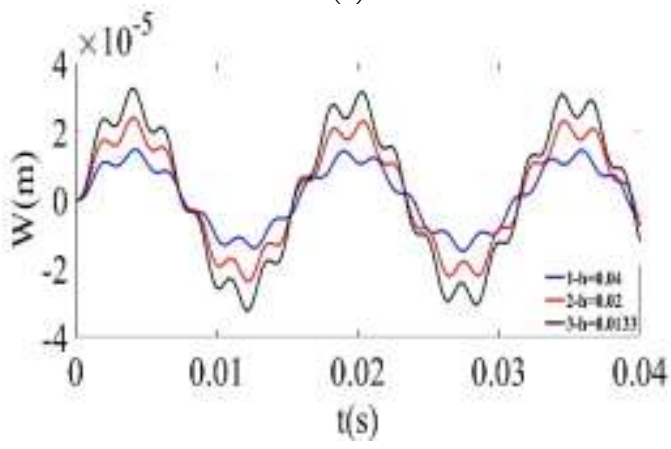

(c)

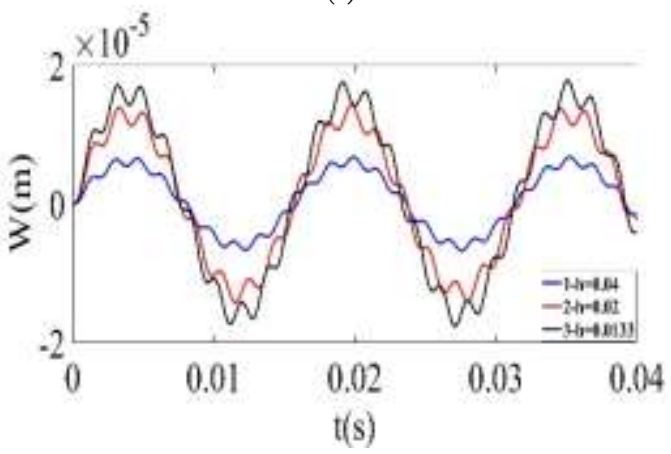

(d)

Figure (7): Influence of thickness of FG-CNT and isotropic material on dynamic response of sandwich cylindrical panels at $V_{C N T}^{*}=0.12$ (a- FGX-CNT, bUD-CNT, c- FGV-CNT, d- FGO-CNT).

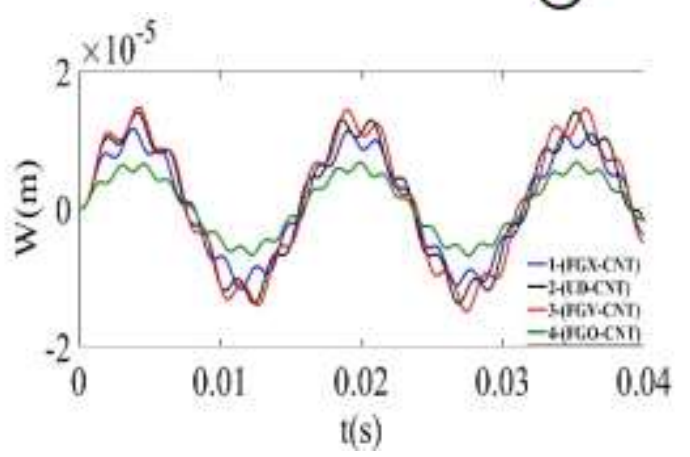

Figure (8): Nonlinear vibration response of sandwich cylindrical panels at $\mathrm{h}=0.04 \mathrm{~m}$ and $V_{C N T}^{*}=$ 0.12 .

\subsection{Effect of Elastic Foundations}

One of the main objectives of the current research is to obtain high natural frequency and reduce the vibration amplitude for the nonlinear dynamic reaction of the functionally graded carbon nanotube cylindrical panel. But not all high vibration is undesirable. Some applications require high vibrations. In the field of this research, the structure used in engineering applications requires a small vibration amplitude to avoid failure. It is noted that (UD, FG-V) panels have the lowest frequency parameters and (FG-O, FG-X) panels have the highest frequency parameters. The Impact of the linear Winkler and Pasternak foundations on the natural frequency for the functionally graded cylindrical panel built by different types of CNT are described in Table 4. It is complete that the elastic foundation has a major influence on the natural frequency. Increasing the value of the elastic foundation leads to constant the natural frequency for all cases and this will be seen when the effect of the elastic foundation is found on the time-deflection curve.

Table 4: Influence of the Winkler and Pasternak foundations on the natural frequency for the CNT and isotropic material for geometry. $\mathrm{a}=\mathrm{b}=1 \mathrm{~m}, \mathrm{R}=1 \mathrm{~m}$, $\mathrm{h}=0.04 \mathrm{~m}$.

\begin{tabular}{|c|c|c|}
\hline $\begin{array}{l}\text { (K1, K2) } \\
\text { Gap/m }\end{array}$ & $\begin{array}{l}\text { Type of } \\
\text { CNT }\end{array}$ & $\begin{array}{l}\text { Natural frequency } \\
\text { (rad/sec) }\end{array}$ \\
\hline \multirow{4}{*}{$(0,0.04)$} & FGX & $\begin{array}{l}49.0362 \\
23.2108 \\
73.1525\end{array}$ \\
\hline & UD & $\begin{array}{l}44.7193 \\
12.1775 \\
70.1683\end{array}$ \\
\hline & FGV & $\begin{array}{c}43.6867 \\
7.5499 \\
69.5138\end{array}$ \\
\hline & $\mathrm{FGO}$ & $\begin{array}{l}62.7467 \\
45.8248 \\
82.6953\end{array}$ \\
\hline
\end{tabular}




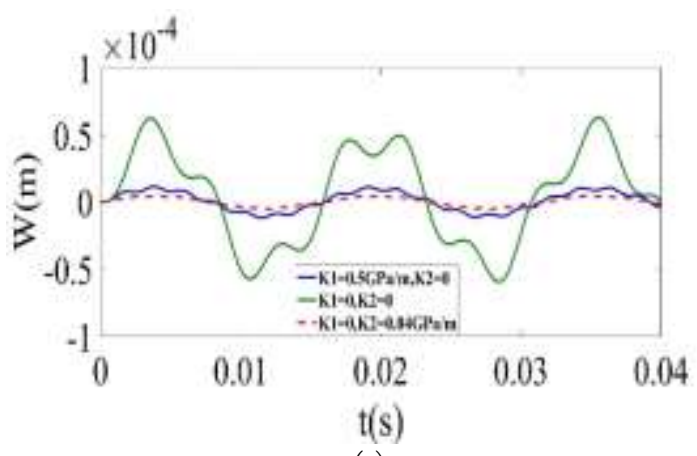

(a)

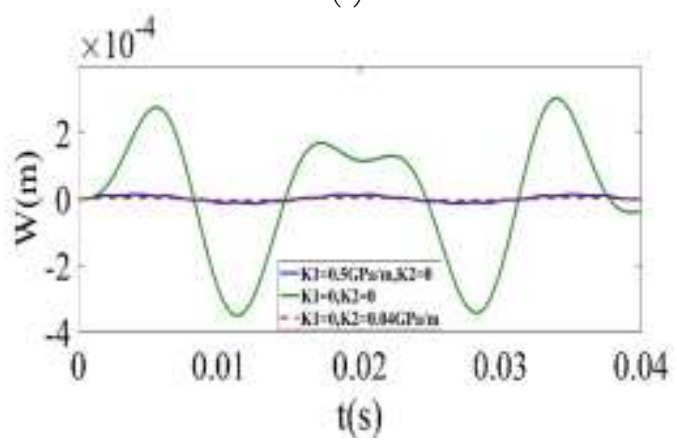

(b)

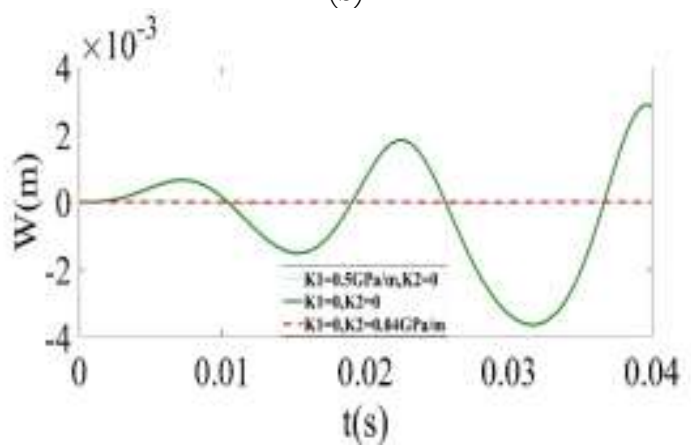

(c)

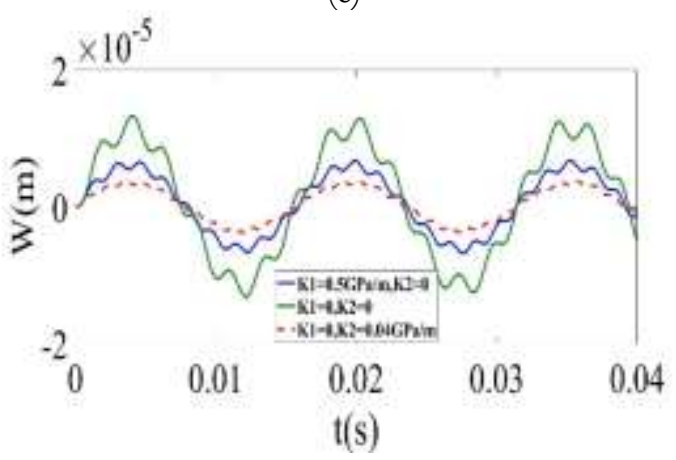

(d)

Figure (9): Influence of the Pasternak and Winkler foundations parameter on the amplitude of dynamic response of sandwich cylindrical panel at $h=0.04 \mathrm{~m}$ and $V_{C N T}^{*}=\mathbf{0 . 1 2}$ (a- FGX-CNT, b- UD-CNT, cFGV-CNT, d- FGO-CNT).

Fig. (9) represented the influence of the Pasternak and Winkler foundations parameter on the amplitude of dynamic response of sandwich cylindrical panel at $Q=4000 \mathrm{~N} / \mathrm{m}^{2}, \Omega=400 \mathrm{rad} / \mathrm{sec}$ and $\mathrm{W} 0=0$. In Figs. of $(a, b, c, d)$ noted that the value of elastic foundation at $(\mathrm{K} 1=0, \mathrm{~K} 2=0.04 \mathrm{Gpa} / \mathrm{m})$ it gives the best behavior to the material and it is offset small increases in the amplitude of natural frequency due to the shear component increases (K2), the amplitude of the vibration increases because the theory (FSDT) takes the effect of shear. As the bending (K1) increases, it will reduce the vibration amplitude. The structure is more stable in FGO-CNT as shown in Fig. (10) represented nonlinear vibration response of sandwich cylindrical panels at $\mathrm{h}=0.04 \mathrm{~m}$ and $\boldsymbol{V}_{\boldsymbol{C N T}}^{*}=$ 0.12.

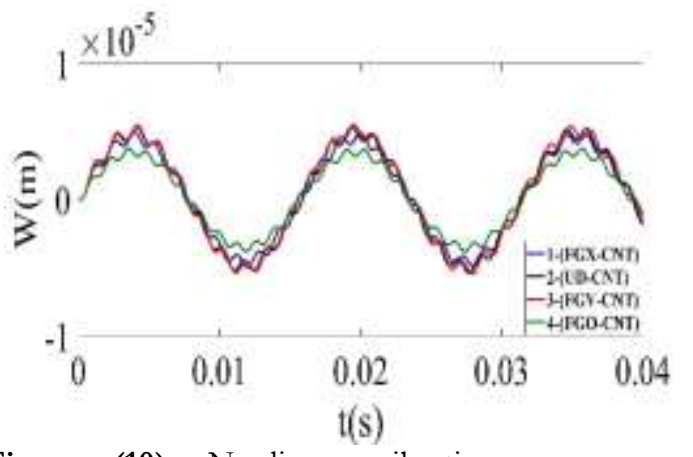

Figure (10): Nonlinear vibration response of sandwich cylindrical panels at $\mathrm{h}=0.04 \mathrm{~m}$ and $\boldsymbol{V}_{\boldsymbol{C N T}}^{*}=$ 0.12 .

\subsection{Effect of Excitation Force}

The influence of harmonic uniform load (Q) on the non-linear dynamic reaction for the FGCNTRC cylindrical panels using four types of CNTs with three different volume fraction are accounted in the Fig.11 It is observed that the three states of the reinforcement have the same behavior under the influence of increased excitation force. Three values are analyzed which are examined in the first-order shear deformation theory $\left(Q=5000 \mathrm{~N} / \mathrm{m}^{2}, Q=\right.$ $\left.4000 \mathrm{~N} / \mathrm{m}^{2}, Q=3000 \mathrm{~N} / \mathrm{m}^{2}\right)$. It can be seen that the excitation force has a hard effect on the amplitude of vibration when increasing the excitation force the vibration amplitude will increase significantly. In another meaning, the cylindrical panel fluctuates stiff at the high value of the excitation force. As shown from the Fig. 11, whenever the value of excitation force decrease, it is offset by an increase in the amplitude on the natural frequency, it is more stable at volume fraction $\boldsymbol{V}_{\boldsymbol{C N T}}^{*}=$ 0.12 at $Q=5000 \mathrm{~N} / \mathrm{m}^{2}$ as:

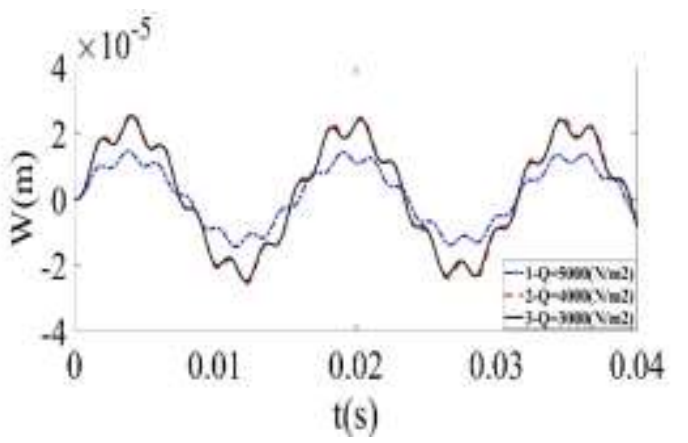

(a) 


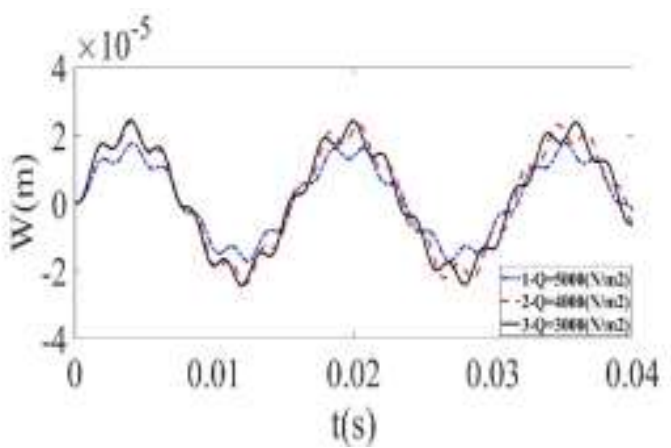

(b)

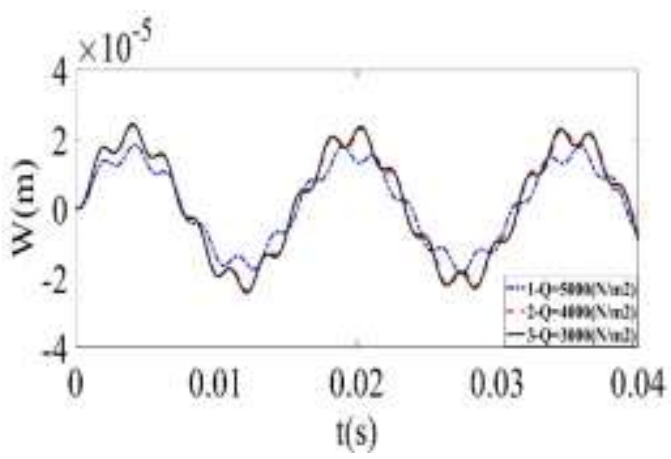

(c)

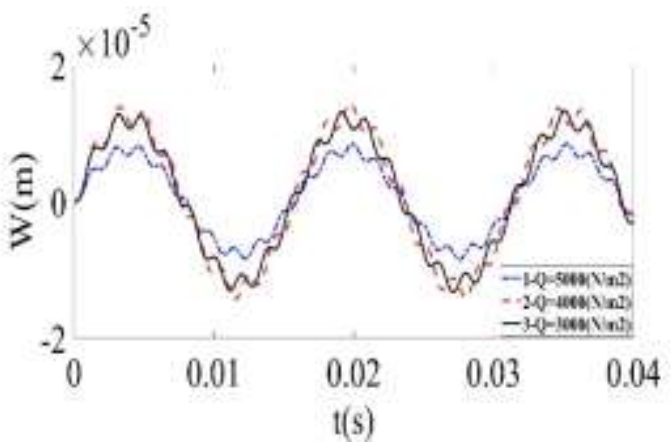

(d)

Figure (11): Influence of excitation force (Q) on the amplitude of vibration for FG-CNTRC cylindrical panel at $\mathrm{a}=\mathrm{b}=1 \mathrm{~m}, \mathrm{~K} 1=\mathrm{K} 2=0, \mathrm{R}=1 \mathrm{~m}, \mathrm{~W} 0=0$ and $V_{C N T}^{*}=0.12$ (a- FGX-CNT, b- UD-CNT, c- FGVCNT, d- FGO-CNT).

\subsection{Effect of Imperfection}

The cylindrical panel contains a certain defect, due to the manufacturing, so it must be taken into consideration through this parameter (W0). Fig.12 represents the effect of initial imperfection on the amplitude of nonlinear dynamic response for functionally graded carbon nanotube sandwich cylindrical panel (CNT, Al, and CNT). The initial imperfection (W0) has a strong effect on the nonlinear response of the panel. It can see that with the value of the initial imperfection $(0,1 \mathrm{e}-05$ and $3 \mathrm{e}-$ 05), the amplitude in the curve of time-deflection increases significantly. As shown from the fig.12, whenever the value of initial imperfection decrease, it is offset by an increase in the amplitude on the natural frequency, it is more stable at volume fraction $V_{C N T}^{*}=0.12$ at $(\mathrm{W} 0=0)$ as:

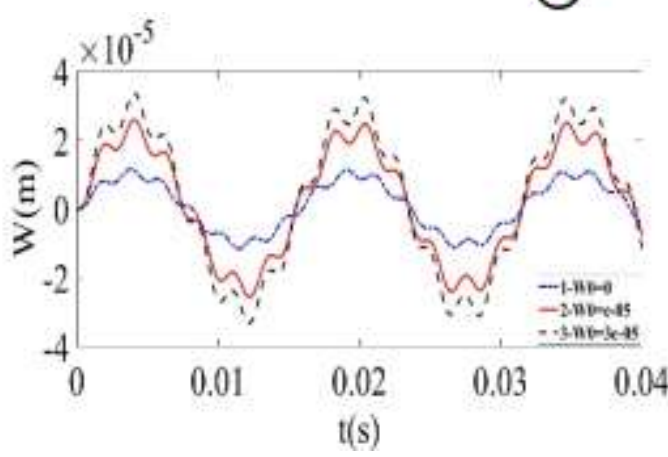

(a)

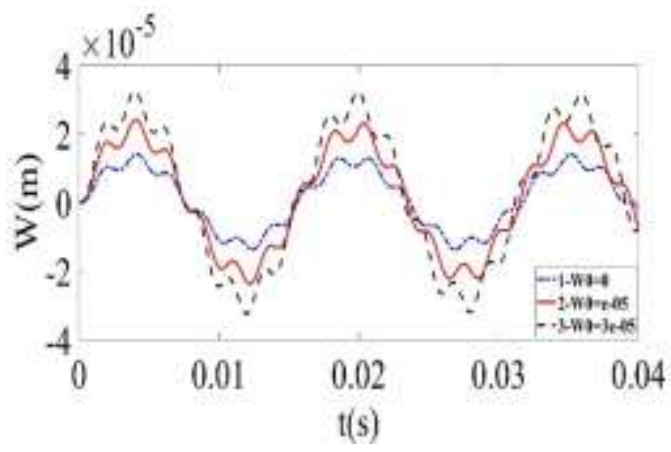

(b)

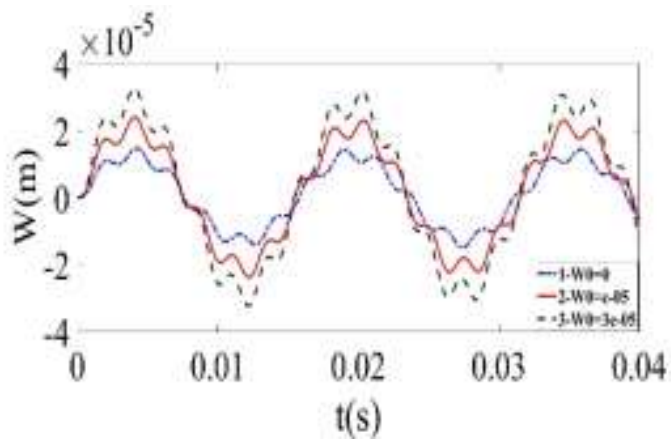

(c)

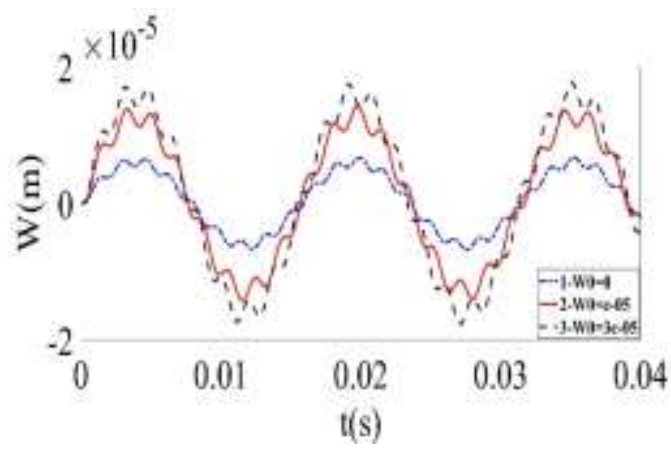

(d)

Figure (12): Influence of imperfection on the amplitude of vibration for FG-CNTRC cylindrical panel at $\boldsymbol{V}_{\boldsymbol{C N} \boldsymbol{T}}^{*}=\mathbf{0 . 1 2} \quad, \mathrm{a}=\mathrm{b}=1 \mathrm{~m}, \mathrm{R}=1 \mathrm{~m}$, $\mathrm{K} 1=\mathrm{K} 2=0$, q0$=4000 \sin 400 \mathrm{t}(\mathrm{a}-\mathrm{FGX}-\mathrm{CNT}, \mathrm{b}-\mathrm{UD}-$ CNT, c- FGV-CNT, d- FGO-CNT).

\section{Conclusions}

Through the analysis of FG-CNT sandwich cylindrical panels nonlinear vibration under various parameters the following conclusions are drawn: 
1. The natural frequencies and the nonlinear vibration amplitude decrease with the volume fraction increase.

2. The natural frequencies and the nonlinear vibration amplitude decrease with the thickness ratio increase.

3. The nonlinear vibration amplitude response increases when increasing the excitation force.

4. The initial imperfection has a minor impact on the nonlinear vibration response of the panel.

5. The elastic foundation has a useful impact on the natural frequency and vibration amplitude.

6. The Pasternak Foundation has a larger impact than the Winkler foundation.

7. The structure formed of FG-CNT present an excellent choice for high-performance of engineering applications.

\section{References:}

[1] P. Zhu, Z. X. Lei, and K. M. Liew, "Static and free vibration analyses of carbon nanotube-reinforced composite plates using finite element method with first-order shear deformation plate theory," Compos. Struct., vol. 94, no. 4, pp. 1450-1460, 2012.

[2] M. H. Yas, A. Pourasghar, S. Kamarian, and M. Heshmati, "Three-dimensional free vibration analysis of functionally graded nanocomposite cylindrical panels reinforced by carbon nanotube," Mater. Des., vol. 49, pp. 583-590, 2013.

[3]J. E. Jam, A. Pourasghar, S. Kamarian, and N. Namdaran, "Free vibration analysis of functionally graded nanocomposite cylindrical panel reinforced by carbon nanotube," Metall. Mater. Eng., vol. 19, no. 3, pp. 203-216, 2013.

[4]A. Alibeigloo, "Free vibration analysis of functionally graded carbon nanotube-reinforced composite cylindrical panel embedded in piezoelectric layers by using the theory of elasticity," Eur. J. Mech., vol. 44, pp. 104-115, 2014.

[5]A. H. Sofiyev, "The vibration and buckling of sandwich cylindrical shells covered by different coatings subjected to the hydrostatic pressure," Compos. Struct., vol. 117, pp. 124-134, 2014.

[6]Z. X. Lei, L. W. Zhang, K. M. Liew, and J. L. Yu, "Dynamic stability analysis of carbon nanotubereinforced functionally graded cylindrical panels using the element-free KP-Ritz method," Compos. Struct., vol. 113, pp. 328-338, 2014.

[7] A. H. Sofiyev, "Influences of shear stresses on the dynamic instability of exponentially graded sandwich cylindrical shells," Compos. Part B Eng., vol. 77, pp. 349-362, 2015.

[8] A. H. Sofiyev, D. Hui, S. E. Huseynov, M. U. Salamci, and G. Q. Yuan, "Stability and vibration of sandwich cylindrical shells containing a functionally graded material core with transverse shear stresses and rotary inertia effects," Proc. Inst. Mech. Eng. Part C J. Mech. Eng. Sci., vol. 230, no. 14, pp. 2376-2389, 2016.

[9] H.-S. Shen, "Postbuckling of nanotube-reinforced composite cylindrical panels resting on elastic foundations subjected to lateral pressure in thermal environments," Eng. Struct., vol. 122, pp.
174-183, 2016

[10] Y. Kiani, "Dynamics of FG-CNT reinforced composite cylindrical panel subjected to moving load," Thin-Walled Struct., vol. 111, pp. 48-57, 2017.

[11] Q. Wang, B. Qin, D. Shi, and Q. Liang, "A semi-analytical method for vibration analysis of functionally graded carbon nanotube-reinforced composite doubly-curved panels and shells of revolution," Compos. Struct., vol. 174, pp. 87-109, 2017.

[12] J. Fan, J. Huang, J. Ding, and J. Zhang, "Free vibration of functionally graded carbon nanotubereinforced conical panels integrated with piezoelectric layers subjected to elastically restrained boundary conditions," Adv. Mech. Eng., vol. 9, no. 7, p. 1687814017711811, 2017.

[13] K. Gao, W. Gao, D. Wu, and C. Song, "Nonlinear dynamic stability of the orthotropic functionally graded cylindrical shell surrounded by Winkler-Pasternak elastic foundation subjected to a linearly increasing load," J. Sound Vib., vol. 415, pp. 147-168, 2018.

[14] A. K. Baltacioğlu and Ö. Civalek, "Vibration analysis of circular cylindrical panels with CNT reinforced and FGM composites," Compos. Struct., vol. 202, pp. 374-388, 2018.

[15] Q. Li, D. Wu, X. Chen, L. Liu, Y. Yu, and W. Gao, "Nonlinear vibration and dynamic buckling analyses of sandwich functionally graded porous plate with graphene platelet reinforcement resting on Winkler--Pasternak elastic foundation," Int. J. Mech. Sci., vol. 148, pp. 596-610, 2018.

[16] P. T. Thang, T. N. Thoi, and J. Lee, "Closedform solution for nonlinear buckling analysis of FG-CNTRC cylindrical shells with initial geometric imperfections," Eur. J. Mech., vol. 73, pp. 483-491, 2019.

[17] P. T. Thang, "Geometrically nonlinear buckling analysis of functionally graded carbon nanotubereinforced cylindrical panels resting on WinklerPasternak elastic foundation," Proc. Inst. Mech. Eng. Part C J. Mech. Eng. Sci., vol. 233, no. 2, pp. 702712, 2019.

[18] Q. Wang, X. Cui, B. Qin, and Q. Liang, "Vibration analysis of the functionally graded carbon nanotube-reinforced composite shallow shells with arbitrary boundary conditions," Compos. Struct., vol. 182, pp. 364-379, 2017.

[19] L. W. Zhang, Z. X. Lei, K. M. Liew, and J. L. $\mathrm{Yu}$, "Static and dynamic of carbon nanotubereinforced functionally graded cylindrical panels," Compos. Struct., vol. 111, pp. 205-212, 2014.

[20] D. H. Bich, D. Van Dung, V. H. Nam, and N. T. Phuong, "Nonlinear static and dynamic buckling analysis of imperfect eccentrically stiffened functionally graded circular cylindrical thin shells under axial compression," Int. J. Mech. Sci., vol. 74, pp. 190-200, 2013.

[21] M. Mirzaei and Y. Kiani, "Free vibration of functionally graded carbon nanotube-reinforced composite cylindrical panels," Compos. Struct., vol. 142, pp. 45-56, 2016. 